\title{
Dynamic Normals as an Industrial Enterprise Management Tool in the Digital Economy
}

\author{
Shestakova E.V. ${ }^{*}$ Sitzhanova A.M. Prytkov R.M. \\ Department of Human Resources, Service and Tourism, Orenburg State University, Orenburg, 460018, Russian \\ Federation \\ *Corresponding author. Email: shestakovaev56@gmail.com
}

\begin{abstract}
Dynamic normals as an industrial enterprise management tool in the digital economy. In the context of the formation of a new technological structure, the digitalization of the economy, digital enterprises formation, characterized by a transition to a qualitatively new level of use of digital technologies in all areas of socioeconomic activity, the relevance of researching directions, trends, and the formation of management tools in rapidly changing conditions is growing. One of the promising approaches is the consideration of the enterprise as a self-organizing system. This article is devoted to the formation of methodology for assessing the stage of enterprise development as a self-organizing microeconomic system. The method of dynamic normals has been suggested as a tool for self-organizing systems management. Variants of managerial influence actions depending on the self-organization factor and stages of company development have been proposed.
\end{abstract}

Keywords: enterprise, management, industrial enterprise, digital economy, correlation analysis, ranking,

self-organization, digital enterprise

\section{INTRODUCTION}

One of the main conditions for the survival and development of modern enterprises in the digital economy is focusing on the implementation of management capabilities and self-organization of social and economic system.

The management of such systems is particularly difficult. This difficulty results in the optimum combination of external managerial influence and internal processes of selforganization. At present, the development of a management mechanism for self-organizing systems at microlevel face a theoretical and practical issue. This mechanism allows combining properties of stability and, at the same time, flexibility and adaptability. The core of the controlling mechanism is the evaluation stage of enterprise development, which in the long run determines the options of managerial influence for social and economic system as it undergoes digital transformation. The developed method of evaluation is intended for:

- monitoring, aimed at rapid identification of critical parameters and determination of the enterprise position (stage) in a self-development cycle;

- $\quad$ analysis, designed to identify benchmarks for selforganizing systems to be adjusted;

- management and development of optimal managerial influence actions according to the stages of development and control parameters of the system identified in the course of monitoring and analysis;

- $\quad$ prediction based on determining the enterprise position in a self-development cycle and its predictable transition to the next stage.

Such foreign scholars as Hermann Haken, Russell L. Ackoff, Norbert Wiener, Paul Krugman, William Ashby, Peter Checkland, Edgar Morin, Humberto Maturana, Stafford Beer, Margaret Mead, Gregory Bateson, and Niklas Luhmann, made great contribution to the theory of selforganisation. Russian scientists S. Kurdyumov, A. Samarsky, B. Kadomtsev, E. Knyazeva, V. Budanov, N. Moiseev, A. Nazaretyan, D. Chernavsky, L. Klimontovich, A. Kolesnikov, G. Ruzavina, A. Ursul, V. Vasylkova, A. Potapov, etc. made valuable contribution to the study of complex self-organizing processes.

The work of such domestic scientists as Delic [1], Hadiguna [2], Macchi [3], Savino [3], Galankashi [4], Helmi [4], Rahim [4], Rane [5], Holbeche [6], Pellizzoni [7], Buganza [7], Annos [8], Thomas [9], Edwards [10].

Application of dynamic normals method while studying the development of socio-economic systems can be found in the works of Syroyezhin [11], Mazhazhikhov [12], Miskhozhev [12], Tonkykh [13], Sizykh [14], Shestakova [15], Prytkov [15], Sitzhanova [15].

Scientific validity is defined by the essence of the author's approach to the problem of enterprise management as a selforganizing socio-economic system. Author's research methodology is based on the method of dynamic normals as a part of the control mechanism for self-organizing systems. This approach creates the basis of forming the mechanism 
of enterprise management as a self-organizing system. The choice of management actions is determined by the ratio of self-organization and the stage of enterprise development. The representation of an enterprise in the concept of selforganization as an open dynamic system causes denial of the static presentation of indicators and its transition to dynamic criteria.

In contrast to the static characteristics, a dynamic criterion is more complex in nature. It determines the trend in economic system, showing the state, to which it should aspire at a given period of time.

One of the tools to analyse the set of indicators in dynamics is the method of dynamic norms. The basis for this method was laid by Professor I.M. Syroyezhin [11], who developed the comprehensive indicator for economic performance assessment systems.

\section{MATERIAL AND METHODS}

The method of dynamic norms is based on the formation of a fixed set of indicators, arranged on the basis of their movement ranking (generally, index growth rate). The factual and normative (reference) order of parameters is compared using correlation analysis tools.

The selection of relative performance serves as the basis of evaluation due to representation of the transformations from one state to another, so the content of the activity is revealed in the changes being generated. This selection also stipulates the assessment of activity level not at the level of one or another indicator, but by its increment, reflecting the dynamics of the object.

Figure 1 is a flowchart describing the method of dynamic norms for assessing the stage of development for social and economic system self-organization.

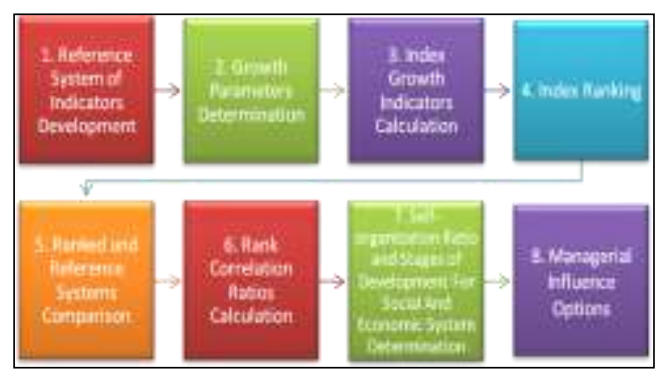

Figure 1 Phases of evaluation for the stage of socioeconomic system development by the dynamic norms method

The necessary condition for the method of dynamic norms application is to create a system of economic development indicators that reflect the state to which it should aspire (reference and normative).

The process of developing a reference system of indicators is to solve two problems: first, to construct the system of indicators assessing the best of the company, and, secondly, to establish reference orders for the growth indicators amending.
The following ones are the criteria for inclusion some indices into the system of indicators formed:

1. dynamic performance and relations with the environment, and also the relations between company subdivisions;

2. lack of duplication (excluding indicators calculated as the ratio between or multiplication of each other, since the method developed measures indicators through their relations growth rate);

3. individualization of the profile (expressed in different units of measurement, selection for the calculation base, small changes in names of indicators, depending on the industry specifics and individual peculiarities of a specific entity, with economic essence of the indicators included in the system not being changed);

4. focusing on tactic activities (control of the strategic aspects of management in the developed system of indicators takes place with the help of a set of reference tactical targets relations monitoring).

5. clear formalization and quantification;

6. limitation in the number (optimal set of indicators includes a variety of 6-15 indicators);

7. managerial influence (all indicators included in the system can be adjusted, each indicator could be a control parameter, which would «return» the company into the stage of dynamic equilibrium);

8. need to group the indicators on the definite basis (optimal basis for grouping various indicators of activity, in our opinion, is the functional orientation of the enterprise internal subsystems).

\section{RESULTS AND DISCUSSION}

Research of foreign and domestic valuation methodologies of the enterprise performance, as well as filtering of various indicators according to the criteria mentioned above allowed us to form a system of indicators represented in Table 1. The next step was the construction of the reference system of indicators used while comparing the actual values of indicators for enterprise development with established values. The reference indicator system is the goal, "target", where the system should strive. From the point of view of self-organization theory, it is an attractor.

Formation of the reference system of indicators was carried out with the use of a method based on the classification of the system's functions, "the golden rule of economics", by constructing the reference ranking graph, the matrix of pair wise comparisons, and also expert methods. The result is a ranked order of growth indicators, reflecting the optimal functioning and development of the company (Table 1).

The established relationship has the following logical interpretation. For example, advancing the pace of profit 
growth in comparison with the revenue growth means lower costs with an increase in sales volumes; profit growth is greater than the rate of production growth, i.e. the marketing policy of the company is effective and its products are competitive and are demanded by the market.

Table 1 Reference system of performance evaluation stage of enterprise development as a self-organizing social and economic system

\begin{tabular}{|l|c|}
\hline \multicolumn{1}{|c|}{ Indices } & Reference rank of movement \\
\hline Profit & 1 \\
\hline Revenue & 2 \\
\hline Production & 3 \\
\hline Long term assets & 4 \\
\hline Wages fund & 5 \\
\hline Average annual headcount of staff & 6 \\
\hline Cost value & 7 \\
\hline Receivables & 8 \\
\hline
\end{tabular}

The effective uses of personnel, as well as earnings growth per employee ratio are expressed in terms of profit growth and a number of employees. The necessary condition for increasing production efficiency, savings of costs and resources is outstripping the pace of earnings growth over the pace of growing costs, payroll, cost of fixed assets, rejects. Similarly, logical relations for all the indicators included in the previously developed system of indicators were established.

The second stage of the enterprise evaluation with the help of dynamic norms method is to determine the actual rate of increase in production and business activities.

We are going to illustrate the implementation of the method of dynamic norms by the example of «Plant A», specializing in the production of sunflower oil. Annual reports, financial statements, explanatory notes of «Plant A» for the years 2012-2019 served as the information basis for this research. Table 2 shows the indicators for the development of «Plant A» in 2012-2019. The indicators of businesses have different names, units of measurement, different coverage of bonds.

In order to analyse all the parameters further we are going to define the continued growth indicators of the enterprise in question (Table 3 ).

Table 2 Key indicators of «Plant A» economic activity for 2012-2019

\begin{tabular}{|c|c|c|c|c|c|c|c|c|}
\hline Indices & 2012 & 2013 & 2014 & 2015 & 2016 & 2017 & 2018 & 2019 \\
\hline $\begin{array}{c}\text { Net income, thousand } \\
\text { rubles }\end{array}$ & 31261 & 26041 & 30637 & 22074 & 31237 & 28388 & 34842 & 85204 \\
\hline $\begin{array}{c}\text { Revenue, thousand } \\
\text { rubles }\end{array}$ & 1122477 & 945488 & 1267528 & 1580166 & 560879 & 1238265 & 1104484 & 1406935 \\
\hline $\begin{array}{l}\text { Volume of output, } \\
\text { tones }\end{array}$ & 108616 & 111650 & 107132 & 99960 & 106750 & 115831 & 102650 & 114103 \\
\hline \begin{tabular}{|c|}
$\begin{array}{c}\text { Average annual cost } \\
\text { of long term assets, } \\
\text { thousand rubles }\end{array}$ \\
\end{tabular} & 49853 & 52933 & 52519 & 51769 & 58435 & 58211 & 59451 & 59084 \\
\hline $\begin{array}{c}\text { Wages fund, thousand } \\
\text { rubles }\end{array}$ & 31468,3 & 34774 & 48869,7 & 39076,8 & 49241,5 & 54922,4 & 54168,9 & 68256 \\
\hline Headcount of staff & 365 & 356 & 332 & 320 & 318 & 307 & 294 & 309 \\
\hline \begin{tabular}{|c|}
$\begin{array}{c}\text { Cost value, thousand } \\
\text { rubles }\end{array}$ \\
\end{tabular} & 1047194 & 883205 & 1179073 & 1492114 & 489824 & 1148643 & 1006131 & 1208400 \\
\hline $\begin{array}{c}\text { Receivables, thousand } \\
\text { rubles } \\
\end{array}$ & 39915 & 37531 & 114973 & 121874 & 198411 & 124585 & 729116 & 503746 \\
\hline \begin{tabular}{|l|} 
Turnover of staff, $\%$ \\
\end{tabular} & 10,88 & 16,44 & 20,18 & 23,04 & 14,54 & 13,84 & 14,15 & 15,68 \\
\hline Net loss of oil, \% & 0,68 & 0,67 & 0,73 & 0,77 & 1 & 0,85 & 0,82 & 0,87 \\
\hline
\end{tabular}

Here we can observe the uneven change of indicators; some indicators of social and economic development have a tendency to fall from year to year, while others remain the same or grow in a certain time interval. The determination of the growth rate does not provide a "cumulative assessment of the final performance, and evaluates the likely change in the conditions in which it takes place" [11, p. 59].

The integral characteristic of the enterprise development can be obtained by identifying the index of movement indicators, defined as continued relations of their growth indicators (Table 4).

The results represented in Table 4 clearly illustrate the change in the numerical structure of values in comparison with Table 3.

The table of correlations for growth performance reflects the development of assessment for individual subsystems of enterprise through selected indicators. In order to obtain a complete picture of enterprise development through the individual motion of separate indicators one should use methods of rank statistics. 
Table 3 Continued growth indicators of economic activity of «Plant A» for 2013-2019

\begin{tabular}{|l|c|c|c|c|c|c|c|}
\hline \multicolumn{1}{|c|}{ Indices } & $\mathbf{2 0 1 3}$ & $\mathbf{2 0 1 4}$ & $\mathbf{2 0 1 5}$ & $\mathbf{2 0 1 6}$ & $\mathbf{2 0 1 7}$ & $\mathbf{2 0 1 8}$ & $\mathbf{2 0 1 9}$ \\
\hline Net income, thousand rubles & 0,833 & 1,176 & 0,721 & 1,415 & 0,909 & 1,227 & 2,445 \\
\hline Revenue, thousand rubles & 0,842 & 1,341 & 1,247 & 0,355 & 2,208 & 0,892 & 1,274 \\
\hline Volume of output, tones & 1,028 & 0,960 & 0,933 & 1,068 & 1,085 & 0,886 & 1,112 \\
\hline $\begin{array}{l}\text { Average annual cost of long term } \\
\text { assets, thousand rubles }\end{array}$ & 1,062 & 0,992 & 0,986 & 1,129 & 0,996 & 1,021 & 0,994 \\
\hline Wages fund, thousand rubles & 1,105 & 1,405 & 0,800 & 1,260 & 1,115 & 0,986 & 1,260 \\
\hline Headcount of staff & 0,975 & 0,933 & 0,964 & 0,994 & 0,965 & 0,958 & 1,051 \\
\hline Cost value, thousand rubles & 0,843 & 1,335 & 1,265 & 0,328 & 2,345 & 0,876 & 1,201 \\
\hline Receivables, thousand rubles & 0,940 & 3,063 & 1,060 & 1,628 & 0,628 & 5,852 & 0,691 \\
\hline Turnover of staff, \% & 1,511 & 1,227 & 1,142 & 0,631 & 0,952 & 1,022 & 1,108 \\
\hline Net loss of oil, \% & 0,985 & 1,090 & 1,055 & 1,299 & 0,850 & 0,965 & 1,061 \\
\hline
\end{tabular}

Table 4 Indices of growth indicators of economic activity of «Plant A» for 2013-2019

\begin{tabular}{|c|c|c|c|c|c|c|c|}
\hline Indices & $\mathbf{2 0 1 3}$ & $\mathbf{2 0 1 4}$ & $\mathbf{2 0 1 5}$ & $\mathbf{2 0 1 6}$ & $\mathbf{2 0 1 7}$ & $\mathbf{2 0 1 8}$ & $\mathbf{2 0 1 9}$ \\
\hline Net income, thousand rubles & 0,833 & 1,412 & 0,612 & 1,964 & 0,642 & 1,351 & 1,992 \\
\hline $\begin{array}{c}\text { Revenue, thousand rubles } \\
\text { Volume of output, } \\
\text { tones }\end{array}$ & 0,842 & 1,592 & 0,930 & 0,285 & 6,220 & 0,404 & 1,428 \\
\hline $\begin{array}{c}\text { Average annual cost of long term } \\
\text { assets, thousand rubles }\end{array}$ & 1,028 & 0,933 & 0,972 & 1,145 & 1,016 & 0,817 & 1,254 \\
\hline Wages fund, thousand rubles & 1,062 & 0,934 & 0,993 & 1,145 & 0,883 & 1,025 & 0,973 \\
\hline Headcount of staff & 0,975 & 0,956 & 1,034 & 1,031 & 0,971 & 0,992 & 1,097 \\
\hline Cost value, thousand rubles & 0,843 & 1,583 & 0,948 & 0,259 & 7,143 & 0,374 & 1,371 \\
\hline Receivables, thousand rubles & 0,940 & 3,258 & 0,346 & 1,536 & 0,386 & 9,320 & 0,118 \\
\hline Turnover of staff, \% & 1,511 & 0,812 & 0,930 & 0,553 & 1,508 & 1,074 & 1,084 \\
\hline Net loss of oil, \% & 0,985 & 1,106 & 0,968 & 1,231 & 0,655 & 1,135 & 1,100 \\
\hline
\end{tabular}

In the fourth step, the ranking of growth rates of indicators, i.e. the process of making room in the ordering of selected indicators takes place. Such kind of rank scoring (Table 5) provides a whole comparable picture of changes, and represents itself as a numeric mapping of structural dynamics characterizing the development of economic system within a given time interval.

The larger value of index corresponds to the highest rank. The smallest value is ranked according to the number of benefiting values.

If some multiple values are equal, the problem of corresponding index movement indicators can be solved by logical differentiation of ranks or by weighing the values obtained under the conditions where the dynamics of activities is implemented.

Thus, in the method of dynamic norms it is proposed to think that "....the ranked number of evaluations measuring a specific set of motion parameters, the whole order of changes, considered as human activities is the measuring economic system efficiency in this time interval in whole" $[11$, p. 70$]$.

Having constructed the actual number of indicators ranging activities of businesses one can start comparing it with the reference rank, presented in Table 1.

There are two possible comparisons of rank orderings, showing properties and different forms of communication subsystems of the enterprise: the one according to deviations and the one according to inversions.

In the first case the deviation is determined, distinguishing rank of an element in the analyzed period of this same rank in the series, taken as a reference. Comparisons of series according to deviations are presented in Table 6 . 
Table 5 Rank evaluation of development indicators of «Plant A» for 2013-2019

\begin{tabular}{|c|c|c|c|c|c|c|c|}
\hline Indices & $\mathbf{2 0 1 3}$ & $\mathbf{2 0 1 4}$ & $\mathbf{2 0 1 5}$ & $\mathbf{2 0 1 6}$ & $\mathbf{2 0 1 7}$ & $\mathbf{2 0 1 8}$ & $\mathbf{2 0 1 9}$ \\
\hline Net income, thousand rubles & 10 & 4 & 8 & 1 & 9 & 2 & 1 \\
\hline Revenue, thousand rubles & 9 & 2 & 7 & 9 & 2 & 9 & 2 \\
\hline Volume of output, tones & 4 & 9 & 3 & 6 & 4 & 8 & 5 \\
\hline $\begin{array}{c}\text { Average annual cost of long term assets, } \\
\text { thousand rubles }\end{array}$ & 3 & 8 & 2 & 5 & 7 & 5 & 9 \\
\hline Wages fund, thousand rubles & 2 & 5 & 9 & 2 & 6 & 7 & 4 \\
\hline Headcount of staff & 6 & 7 & 1 & 7 & 5 & 6 & 7 \\
\hline Cost value, thousand rubles & 8 & 3 & 5 & 10 & 1 & 10 & 3 \\
\hline Receivables, thousand rubles & 7 & 1 & 10 & 3 & 10 & 1 & 10 \\
\hline Turnover of staff, \% & 1 & 10 & 6 & 8 & 3 & 4 & 8 \\
\hline Net loss of oil, \% & 5 & 6 & 4 & 4 & 8 & 3 & 6 \\
\hline
\end{tabular}

Table 6 Rank evaluation Comparison of actual performance ranks of «Plant A» for 2013-2019 with standard deviations of the reference rank

\begin{tabular}{|c|c|c|c|c|c|c|c|c|}
\hline \multirow[t]{2}{*}{ Indices } & \multirow[t]{2}{*}{ Reference rank } & \multicolumn{7}{|c|}{$\begin{array}{l}\text { Deviations for the compared (Table 5) } \\
\text { and reference ranks (Table 1) }\end{array}$} \\
\hline & & 2013 & 2014 & 2015 & 2016 & 2017 & 2018 & 2019 \\
\hline $\begin{array}{l}\text { Net income, thousand } \\
\text { rubles }\end{array}$ & 1 & 9 & 3 & 7 & 0 & 8 & 1 & 0 \\
\hline $\begin{array}{l}\text { Revenue, thousand } \\
\text { rubles }\end{array}$ & 2 & 7 & 0 & 5 & 7 & 0 & 7 & 0 \\
\hline Volume of output, tones & 3 & 1 & 6 & 0 & 3 & 1 & 5 & 2 \\
\hline $\begin{array}{c}\text { Average annual cost of } \\
\text { long term assets, } \\
\text { thousand rubles }\end{array}$ & 4 & -1 & 4 & -2 & 1 & 3 & 1 & 5 \\
\hline $\begin{array}{c}\text { Wages fund, thousand } \\
\text { rubles }\end{array}$ & 5 & -3 & 0 & 4 & -3 & 1 & 2 & -1 \\
\hline Headcount of staff & 6 & 0 & 1 & -5 & 1 & -1 & 0 & 1 \\
\hline $\begin{array}{l}\text { Cost value, thousand } \\
\text { rubles }\end{array}$ & 7 & 1 & -4 & -2 & 3 & -6 & 3 & -4 \\
\hline $\begin{array}{c}\text { Receivables, thousand } \\
\text { rubles }\end{array}$ & 8 & -1 & -7 & 2 & -5 & 2 & -7 & 2 \\
\hline Turnover of staff, $\%$ & 9 & -8 & 1 & -3 & -1 & -6 & -5 & -1 \\
\hline Net loss of oil, $\%$ & 10 & -5 & -4 & -6 & -6 & -2 & -7 & -4 \\
\hline
\end{tabular}

The disadvantage of comparing the deviations is the assessment of each element of the system in isolation, without considering the relations between elements.

In order to build a complete picture of the object the method of comparison by inversions is used. This method takes into account all the permutations of the elements while ranking. The order of ranks under analysis, as a rule, is "confused", modified, "repositioned" relative to a given reference arrangement of the indicators. This change of a normal, fixed order in the reference number is called inversion.

The easiest way to determine the inversion lies in the following: one counts the amount of numbers with a lower rank and also numbers of the considered rank located below. The result is the inversion.

Table 7 shows the comparison of the actual and reference series by method of inversions. 
Table 7 Comparison of actual performance ranking of «Plant A» with the reference rank in inversions

\begin{tabular}{|c|c|c|c|c|c|c|c|c|}
\hline \multirow[t]{2}{*}{ Indices } & \multirow{2}{*}{$\begin{array}{c}\text { Reference } \\
\text { rank }\end{array}$} & \multicolumn{7}{|c|}{$\begin{array}{l}\text { The number of items in inversion for the compared rank with respect to each } \\
\text { element of the reference rank }\end{array}$} \\
\hline & & 2013 & 2014 & 2015 & 2016 & 2017 & 2018 & 2019 \\
\hline $\begin{array}{l}\text { Net income, thousand } \\
\text { rubles }\end{array}$ & 1 & 9 & 3 & 7 & 0 & 8 & 1 & 0 \\
\hline $\begin{array}{l}\text { Revenue, thousand } \\
\text { rubles }\end{array}$ & 2 & 8 & 1 & 6 & 7 & 1 & 7 & 0 \\
\hline Volume of output, tones & 3 & 3 & 6 & 2 & 4 & 1 & 6 & 2 \\
\hline $\begin{array}{c}\text { Average annual cost of } \\
\text { long term assets, } \\
\text { thousand rubles }\end{array}$ & 4 & 2 & 4 & 1 & 3 & 4 & 3 & 5 \\
\hline $\begin{array}{l}\text { Wages fund, thousand } \\
\text { rubles }\end{array}$ & 5 & 1 & 2 & 4 & 0 & 3 & 4 & 1 \\
\hline Headcount of staff & 6 & 2 & 3 & 0 & 2 & 2 & 3 & 2 \\
\hline $\begin{array}{l}\text { Cost value, thousand } \\
\text { rubles }\end{array}$ & 7 & 3 & 1 & 1 & 3 & 0 & 3 & 0 \\
\hline $\begin{array}{l}\text { Receivables, thousand } \\
\text { rubles }\end{array}$ & 8 & 2 & 0 & 2 & 0 & 2 & 0 & 2 \\
\hline Turnover of staff, $\%$ & 9 & 0 & 1 & 1 & 1 & 0 & 1 & 1 \\
\hline Net loss of oil, $\%$ & 10 & 0 & 0 & 0 & 0 & 0 & 0 & 0 \\
\hline
\end{tabular}

The advantage of the inversion procedure is not assessing each element separately, and comparing the observed deviations, but analyzing all the permutations of the elements ranked.

In order to interpret the evaluations presented in Tables 6 and 7 , the correlation analysis tools are used. Score deviations make it possible to determine the Spearman's coefficient of rank correlation; the inversion evaluation is used in the determination of the Kendall's coefficient of correlation.

Spearman's rank correlation coefficient in our sample (in the absence of the same ranks) is defined by the formula (1):

$$
r_{s}=1-6 \frac{\sum d^{2}}{N\left(N^{2}-1\right)} \text {, where }
$$

$\Sigma \mathrm{d} 2$ - the sum of the squares for the differences between the ranks;

$\mathrm{Ta}$ and $\mathrm{Tb}$ - amendments to the same ranks;

$\mathrm{N}$ - the number of attributes involved in the ranking.

The following one is an example of calculating the Spearman coefficient based on the development of indicators of «Plant A» in 2013. Similarly, the coefficients are determined for the remaining period of the enterprise development (Table 8).

$$
r_{s_{2006}}=1-6 \frac{(81+49+1+1+1+0+1+1+64+25)}{=-0,406}
$$

Having regulated the Spearman coefficients one should determine the critical value $r_{s}$ for a given number of elements (using a table of critical values of the Spearman rank correlation coefficient). In our example, for $\mathrm{N}=10$ the critical value is 0.64 . If the calculated value $r_{s}$ exceeds a critical one or at least is equal, then a real number is close to the reference one.

$$
r_{k}=1-\frac{4 \sum_{i=1}^{N} m_{s}}{N(N-1)}, \text { where }
$$

rk - Kendall's coefficient of rank correlation;

$\mathrm{N}$ - the number of indicators included in the assessment system;

ms- sum of inversions.

Thus, based on the data presented in Table 6, Kendall tau rank correlation coefficient in 2013 is determined as follows:

$$
r_{k 2006}=1-\frac{4 \times 24}{10(10-1)}=-0,067
$$

Similarly, Kendall's tau $(\tau)$ coefficients, characterizing the development of enterprises in 2014-2019, are determined (Table 8).

Kendall's and Spearman's coefficients give the estimate of the proximity of one rank to another one (reference rank) over the interval from +1 to -1 . The result equal to $(+1)$ is obtained, if the ranks of both pairs for orders are arranged in the same sequence (i.e., the coincidence of the order being compared to the reference one). A negative value is evidence of the full differently directed motions of indicators for the actual performance rank and the reference rank.

Negative values of Kendall's and Spearman's coefficients obtained in 2013, 2015 and 2018, show the development of the enterprise, which differs significantly from the desired (planned) operation modes.

The calculation of rank correlation coefficients allows to determine the index integrating three-dimensional (evaluation by deviations) and structural (estimated by inversions) side of the enterprise into a single assessment. This ratio is a tool for determining the stage of selforganization of social and economic system, thus appearing as an integral factor of self-organizing social and economic system (Kso). The degree of relationship between the values of the actual parameters and the reference series indicates the absolute value of the correlation coefficient. 
Table 8 shows the values of coefficients obtained earlier

The final evaluation Kso obtained on the basis of two correlation coefficients rs and rk is determined as follows:

$$
K_{s o}=\frac{\left(1+r_{s}\right)\left(1+r_{k}\right)}{4}
$$

than those of Spearman (rs) and Kendall (rk) and are calculated on the basis of their self-organization coefficients (Kso) in 2013-2019.

Table 8 Coefficients of self-organization of «Plant A» for 2013-2019

\begin{tabular}{|c|c|c|c|c|c|c|c|}
\hline Coefficients & $\mathbf{2 0 1 3}$ & $\mathbf{2 0 1 4}$ & $\mathbf{2 0 1 5}$ & $\mathbf{2 0 1 6}$ & $\mathbf{2 0 1 7}$ & $\mathbf{2 0 1 8}$ & $\mathbf{2 0 1 9}$ \\
\hline Spearman's $\left(\mathbf{r}_{\mathbf{s}}\right)$ & $-0,406$ & 0,127 & $-0,042$ & 0,152 & 0,055 & $-0,285$ & 0,588 \\
\hline Kendall's $\left(\mathbf{r}_{\mathbf{k}}\right)$ & $-0,333$ & 0,067 & $-0,067$ & 0,111 & 0,067 & $-0,244$ & 0,422 \\
\hline Self-organization $\left(\mathbf{K}_{\mathbf{s o}}\right)$ & 0,099 & 0,301 & 0,223 & 0,320 & 0,281 & 0,135 & 0,565 \\
\hline
\end{tabular}

Kso value changes over the range from 0 to 1 . The coefficient of 1 indicates the coincidence of the actual and the reference system performance set in the order when all relations established for growth indicators take place. This ratio is typical for the most effective level of implementation for financial, personnel, marketing, and investment policy of the company. The closer the value of Kso to 1 is, the greater is the standard rate of growth observed. The value of 0 indicates the inefficiency of business, when the actual index ratio is inconsistent with the motion parameters.

Based on statistics taken in numerical interpretation of the correlation coefficients the proximity of two operation modes can be estimated: actual and reference ones. Table 9 shows the degree of closeness between the actual and the reference value for the indicators and the relevant options of managerial influence depending on the value of selforganization coefficient.
The ratio of self-organization and managerial influence processes depends on the Kso value in the following way: the level of self- enterprise subsystems also increases with the increase of the correlation coefficient.

Each stage of self-organization process corresponds to the definite value of the self-organization coefficient. Thus, the enterprise in a cycle of self-development can be found in the following areas, i.e.: bifurcation area, critical area, normative and reference areas.

The trajectory of "Plant A" development for 2013-2019, built on the basis of self-organization calculated coefficients is shown in Figure 2.

Table 9 Control actions options for the system of self-organization coefficient different values

\begin{tabular}{|c|c|c|c|c|}
\hline $\begin{array}{c}\text { Integral } \\
\text { Coefficient } \\
\text { of } \\
\text { Self- } \\
\text { Organizatio } \\
\text { n Value }\end{array}$ & $0-0,2$ & $0,2-0,4$ & $\mathbf{0 , 4 - 0 , 7}$ & $0,7-1$ \\
\hline $\begin{array}{c}\text { Degree of } \\
\text { Closeness } \\
\text { between } \\
\text { Reference } \\
\text { Value and } \\
\text { Actual } \\
\text { Performance }\end{array}$ & Absent & Weak & Moderate & Strong \\
\hline $\begin{array}{l}\text { Self-organi- } \\
\text { sation Stage }\end{array}$ & $\begin{array}{l}\text { Development of a new } \\
\text { self-organi- } \\
\text { sation model for } \\
\text { subsystems } \\
\end{array}$ & $\begin{array}{l}\text { Stage of } \\
\text { transition }\end{array}$ & Dynamic equilibrium & Dynamic equilibrium \\
\hline Area Name & Bifurcation & Critical & Normative & Reference \\
\hline $\begin{array}{l}\text { Managerial } \\
\text { Influence } \\
\text { Options }\end{array}$ & $\begin{array}{l}\text { Targeted self- } \\
\text { organization, } \\
\text { development of a new } \\
\text { self-organizing } \\
\text { structure }\end{array}$ & $\begin{array}{c}\text { Targeted self-organization, } \\
\text { development of a new self- } \\
\text { organizing } \\
\text { structure }\end{array}$ & $\begin{array}{l}\text { Self-organization and intended effect } \\
\text { correspond to the same } \\
\text { degree }\end{array}$ & $\begin{array}{l}\text { Prevalence of self-organization, if } \\
\text { necessary - regulation aimed at a } \\
\text { return to the } \\
\text { equilibrium state }\end{array}$ \\
\hline
\end{tabular}




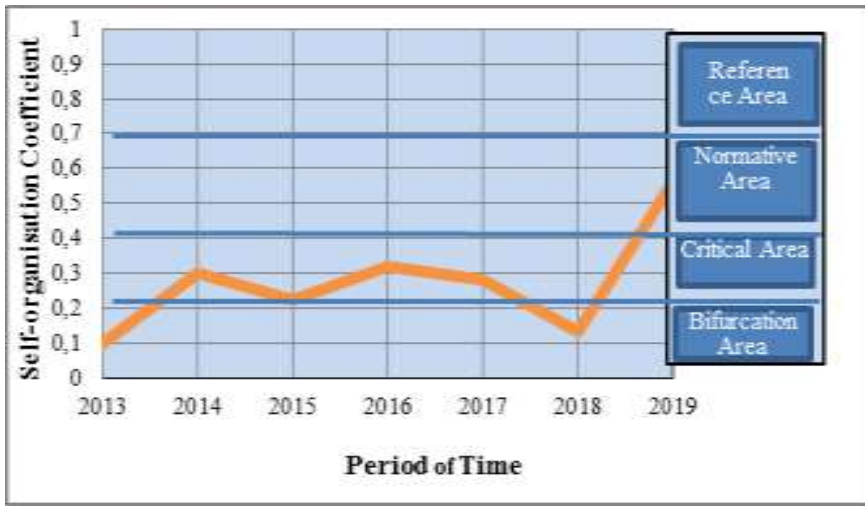

Figure 2 Correlation of self-organization coefficients with the stages of «Plant A» development in 2013-2019

\section{CONCLUSION}

In general, the presented graph indicates that the enterprise is located in the critical area, where purposeful managerial impact (influence) dominates, and self-organizing internal subsystems are minimized. In 2018 the company got into the bifurcation area which is characterized by the revision of the strategy, setting new goals, and also creates a qualitatively new self-organizing structure. At present, the enterprise is entering the stage of dynamic equilibrium. In the future, optimal managerial influence will contribute to the realization of the enterprise potential of selforganization and the achievement of the development trajectory, as close as possible to the standard.

To sum up, we should note that the considered method of dynamic norms has a number of advantages:

- it is based on the assessment of the system effectiveness in the form of growth indicators (i.e., the dynamic property as the main parameter of the self-organization of social and economic system is taken into account, as well as the irregular movement of various indicators in the course of time) ;

- it allows you to bring indicators of various dimensions to the comparable numerical characteristic;

- a small number of indicators can reflect the range of "real dynamical states" [11, p. 90 ] in the appraiser;

- it allows one to analyse the internal structure of an object and the ratio of the individual parts;

- it reflects a diverse set of properties of all interdependent elements, emphasizing the uniqueness of the participation of each element in the formation of a common result;

- it is suitable for the evaluation of development of social and economic systems at macro-, meso- and microlevels .

The method of dynamic norms is the tool of choice for managerial influence on the economic system, acting as the element of a holistic mechanism of management of the social and economic system.

\section{ACKNOWLEDGMENT}

The studies were carried out with the financial support of the Russian Federal Property Fund in the framework of the scientific project No. 20010-00459\20

\section{REFERENCES}

[1] M. Delic, D.R. Eyers The effect of additive manufacturing adoption on supply chain flexibility and performance: An empirical analysis from the automotive industry, in: International Journal of Production Economics, Volume 228, October 2020, № 107689.

[2] R.A. Hadiguna Performance measurement for sustainable supply chain in automotive industry: A conceptual framework, in: International Journal of Value Chain Management, Volume 5, Issue 3-4, October 2011, pp. 232-250.

[3] M. Macchi, M. Savino M., I. Roda Analysing the support of sustainability within the manufacturing strategy through multiple perspectives of different business functions, in: Journal of Cleaner Production, Volume 258, 10 June 2020, № 120771.

[4] R. Galankashi, S.A.Helmi, A. Rahim, F. Rafiei Agility assessment in manufacturing companies, in: Benchmarking, 2019, 26, pp. 2081-2104.

[5] S. Rane, Y. Narvel, B. Bhandarkar Developing strategies to improve agility in the project procurement management (PPM) process: Perspective of business intelligence, in: Business Process Management Journal, 2019, pp. 2081-2104.

[6] L. Holbeche Organisational effectiveness and agility, in: Journal of Organizational Effectiveness, 2018, 5, pp. 302-313.

[7] E. Pellizzoni, T. Buganza When agility meets open innovation: two approaches to manage inbound projects, in: Creativity and Innovation Management, 2019, 28, pp. 464-476.

[8] Annos P. Martini Learning in an agile setting: A multilevel research study on the evolution of organizational routines in: Journal of Business Research, 2020, №110, pp. 554-566.

[9] Thomas Developing an integrated quality network 
for lean operations systems, in: Business Process Management Journal, 2018, 24, pp. 1367-1380.

[10] Edwards, Cooper, Vedsmand, Nardelli Evaluating the ag-ile-stage-gate hybrid model: Experiences from three SME manufacturing firms in: /International Journal of Innovation and Technology Management, 2019, 116, pp. 554-566.

[11] Mazhazhikhov, E. Miskhozhev Dynamic Regulatory Models of diagnosis economic sustainability of industrial, in: Bulletin of the St. Petersburg University of the Russian State Fire Service, 2012, pp. 89-96.

[12] Syroezhin Improving the system of indicators of efficiency and quality, Moscow, Economics, 1980, 192 p.

[13] Tonkikh Observance of the balance of interests in Russian corporations, in: Audit and financial analysis, 2007, 1, pp. 329-390. Sizykh, D. S. Dynamic graphanalytical model of "related indicators" for assessing the growth of enterprise performance and labor productivity / D. S. Sizykh, N. V. Sizykh // Economics. - 2012. - No. 87. - S. 325-330

[14] D. Sizykh Dynamic graph-analytical model of "related indicators" for assessing the growth of enterprise performance and labor productivity, in: Economics, 2012, 87, pp. 325-330.

[15] E. Shestakova, R. Prytkov, L. Dokashenko, A. Sitzhanova Developing the export potential of a region and their practical approbation, Opcion,2019, Vol. 35, Spec. Iss. 19, pp. 46-73. 